Revista de Psicología Vol. 33 (2), 2015 (ISSN 0254-9247)

\title{
Recepción fílmica y la formación de identidades sociales vinculadas a la categoría nación
}

\author{
Rolando Pérez Sánchez ${ }^{1}$, Diana Alfaro Chavarría ${ }^{2}$ y Melissa Mora Pineda ${ }^{3}$ \\ Instituto de Investigaciones Psicológicas y Universidad de Costa Rica
}

\begin{abstract}
Este estudio cualitativo aborda las relaciones entre la recepción fílmica y la construcción de la identidad social asociada a la categoría nación ante filmes evocadores de comparación intergrupal. Se seleccionaron dos películas estadounidenses que facilitaron la tarea de contraste intergrupal. Se organizaron cinco grupos de discusión de cuatro a seis personas. Cada grupo observó los dos filmes. Los resultados indican la presencia de favoritismo endogrupal luego de la exposición a ambos filmes. Se distinguió un núcleo común de la identidad asociada a la categoría nación. Sin embargo, se presentan diferencias en la descripción de la identidad social atribuibles al encuadre narrativo de ambos filmes. Las evidencias aportan al estudio contextualista de la categorización social asociados a la recepción fílmica.

Palabras clave: recepción fílmica, identidad social, encuadres narrativos.
\end{abstract}

\section{Reception of films and the formation of social identities related to nation}

This qualitative study addresses the relationship between film reception and the formation of social identity related to the nation in reference to two evocative films used for intergroup comparison purposes. Two American films were selected to facilitate the task of intergroup contrast. Five focus groups were created, and were composed of four to six persons each. Each group saw both films. Results indicate the presence of in-group favoritism after viewing both films. A common core identity related to the nation was built after viewing both films; however, differences arise in the description of social identity attributed to the narrative frame of each film. Results contribute to the study of social categorization processes associated with film reception.

Keywords: Film reception, social identity, narrative frames.

1 Ph.D en Psicología Social y profesor en la Universidad de Costa Rica. Instituto de investigaciones Psicológicas, Universidad de Costa Rica. Dirección postal: Apartado postal 11501-2060, San José, Costa Rica. Contacto: rolarez@gmail.com

2 Bachiller en Psicología y asistente de investigación en la Universidad de Costa Rica. Contacto: marcelamaiden18@gmail.com

3 Licenciada en Psicología y asistente de investigación en la Universidad de Costa Rica. Contacto: mmmp12@hotmail.com 
Este estudio aborda las relaciones entre la recepción fílmica y la construcción de la identidad social asociada a la categoría nación en un contexto mediático de comparación intergrupal. En la construcción de las identidades sociales, el papel de los medios de comunicación cobra especial relevancia en la construcción de las identidades sociales, considerando los actuales procesos de globalización cultural acelerada que impactan en las culturas locales, haciéndolas más interdependientes (Pérez, 2003a). La formación de las identidades sociales en este contexto, se constituye en un proceso de negociación, hibridación, y de narración, que es tematizado y escenificado por los medios de comunicación, en una trama comunicativa que abarca desde las relaciones cara a cara hasta la comunicación mediada por computadora (García Canclini, 1989, Livingstone, 1998, Martín Barbero, 2002). En el caso específico de la recepción y el proceso de apropiación fílmica, estos van a estar determinados de forma relativa por los contenidos de la oferta mediática y la forma cómo estos son estructurados (Pérez, 2003b). Estos contenidos incluyen indicaciones tanto formales, estéticas, dramatúrgicas, narrativas, semánticas y pragmático-lingüísticas que ofrecen pistas para su interpretación. Una forma de acceso a estas indicaciones es atendiendo al estudio de los encuadres (Frame Analysis).

Originalmente propuesto para la investigación de noticias, se entiende por encuadre las formas en que se organiza la información mediática, fílmica en este caso (Scheufele, 1999, 2004). Aplicado a los filmes, los encuadres ofrecen información que permiten comprender y posicionarse frente a la historia y la narración, las características de los personajes y la interacción entre ellos. Dicha información se organiza en forma de esquemas cognoscitivos, cuyo objetivo es orientar la interpretación del mensaje. No obstante, la comprensión y valoración última del mensaje está a cargo del receptor, el cual, precisamente en la fase de comprensión recurre a sus propios encuadres para aceptar, 
asimilar o por el contrario, rechazar el encuadre mediático. La recepción fílmica implica entonces la negociación de las identidades personales y sociales respecto al encuadre de la película vista (Pérez, 2002). En la presente investigación interesa estudiar específicamente la formación de identidades sociales que se organizan a partir de la categoría nación, entendida esta como un componente de la identidad social en el sentido expuesto por Tajfel (1984): la identidad social es "parte del autoconcepto del individuo que se deriva del conocimiento de su pertenencia a un grupo (o grupos) social con el significado valorativo y emocional asociado a dicha pertenencia" (Tajfel, 1984, p. 292). El significado de la pertenencia a un grupo nación para el sí-mismo, en la comparación con otros grupos nación, depende del grado de prominencia (salience) de dicha categoría en el contexto del conjunto de categorías sociales que se comparten con el propio grupo (endogrupo) y que a su vez son diferentes de las atribuidas a otros grupos (exogrupos).

La categorización, considerada como el proceso que subyace a la formación de un grupo (Turner \& Reynolds, 2003), es un modo de organización del conocimiento sobre los otros, de acuerdo con Tajfel (1984) es un "sistema de orientación que ayuda a crear y definir el puesto del individuo en la sociedad” (p. 292). Según la teoría de la categorización de sí-mismo (Turner \& Reynolds, 2003, McGarthy, 1999): (a) las personas categorizan a otros y a sí mismos de acuerdo a la pertenencia a determinados grupos. Este proceso se expresa en los contextos comunicativos, en los espacios de relación con otros de un mismo grupo o de otro distinto. Para el presente estudio interesa la comparación entre el endogrupo y el exogrupo a partir de la percepción de la pertenencia a un grupo nación como resultado de la recepción fílmica; (b) la relación inversa que se da entre la prominencia de los niveles personal y social, y puede estar condicionada y puede ser condicionante de la percepción de la relevancia de la categoría nación; (c) la prominencia de la categoría que indica la pertenencia a un grupo nación en la relación endo-exogrupo, puede dar lugar a un proceso que oscila entre la identificación con el grupo categorial, en tanto relevante para la identidad personal, hasta la despersonalización de la percepción 
del auto-concepto en el que se tiende a incrementar la identidad percibida (semejanza, equivalencia, intercambiabilidad) entre el sí-mismo y los miembros del endogrupo (y la diferencia respecto a los individuos del exogrupo).

Los trabajos de Harwood (1999), Abrams, Giles y Reid (2004), Abrams y Giles (2007), y Trepte (2006) indagan precisamente en la asociación entre la identidad social y la recepción y la comprensión del material televisivo o fílmico. Harwood (1999) y Abrams, Giles y Reid (2004) asumen que la elección específica de la oferta mediática está determinada por la gratificación de diferentes categorías identitarias que contribuyen a una auto-estima positiva y a su vez la elección tiene carácter recíproco, pues existen evidencias de que la elección de determinados programas puede aumentar la gratificación asociada a determinadas categorías sociales, por ejemplo, edad o grupo étnico.

Abrams, Giles y Reid (2004), y Abrams y Giles (2007) exploran la idea de que los individuos seleccionan o evitan los contenidos televisivos en un esfuerzo por encontrar satisfacción a sus necesidades de identidad social, de forma tal que el consumo mediático tendrá lugar dependiendo de la motivación de los individuos por crear una distintividad positiva del endogrupo respecto al exogrupo, usando estrategias de movilidad o creatividad social en el caso de confirmar el estatus quo o bien la competencia social para afrontarlo. Por su parte, Trepte (2006) señala, igualmente, que el proceso de selección de los contenidos mediáticos se da a partir de la búsqueda de una autoestima positiva, solo que esta vez la prominencia de alguna categoría, previa a la recepción y que definió la escogencia, va a estar definiendo el proceso de categorización y por ende el de comparación social. Este proceso facilita el favoritismo endogrupal, la evaluación negativa del exogrupo y la distintividad positiva, lo que finalmente permite la selección y recepción del contenido de los medios de entretenimiento.

El presente estudio va más allá de los estudios precedentes al considerar que la sola exposición al material fílmico posibilita la construcción ad-hoc de identidades sociales. Las identidades sociales actualizadas o construidas van a variar según la categoría social más saliente en la película. 
La conformación de esta identidad, producto del proceso de recepción fílmica, acontece en un proceso de comparación intergrupal, generándose representaciones específicas, tanto del endogrupo como del exogrupo. De esta manera, se supondría que películas distintas pero con una misma categoría social saliente, como en el caso del presente estudio la categoría nación, van a generar identidades nacionales con contenidos comunes pero también con rasgos distintivos. Se prevé que esto es posible gracias a las particularidades del encuadre fílmico que ofrece pistas o modelos de interpretación del filme y de posicionamiento respecto a las identidades sociales que ellos evocan.

Conforme a lo expuesto, el presente estudio se orienta específicamente a indagar la relación existente entre la exposición a dos películas estadounidenses evocadoras de comparación intergrupal y la construcción de las identidades sociales asociadas a la categoría nación producto de su visionado. La investigación realizada es de tipo cualitativo. Los resultados presentados a continuación pertenecen a una investigación más amplia sobre la formación de identidades sociales asociadas a la categoría nación y la recepción de films.

\section{Método}

\section{Participantes}

Se recurrió a un muestreo por criterio, con sujetos voluntarios. Los participantes fueron 22 jóvenes (11 hombres y 11 mujeres), que asisten a universidades públicas de San José, Costa Rica, con edades entre los 18 y 22 ańos, y cursan carreras de las ciencias naturales y de las ciencias sociales. Los participantes firmaron un consentimiento informado, donde se detallaron los objetivos, las actividades a realizar, y se les señalaba el compromiso de protección de la información ofrecida. 


\section{Procedimiento}

El proceso de construcción del dato constó de tres fases: la primera fase se dirigió a la selección del filme, la segunda fase buscó hacer una caracterización del grupo sociocultural con el que se trabaja, y en la tercera fase se llevó a cabo los grupos de discusión.

Selección de los filmes. Se trabajó con dos películas producidas en Estados Unidos. La elección de ese país permitió la comparación y el contraste intergrupal, ya que ofrecen condiciones de vida y culturales diferentes a las de Costa Rica. Para la selección de los filmes que sirvieron de estímulo para evocar la comparación intergrupal se consultó a 7 jueces, quienes evaluaron cuatro filmes de acuerdo a los siguientes criterios: (a) los filmes debían presentar escenas de la vida cotidiana estadounidense que a su vez reflejen estilos de vida propios de una cultura individualista atribuidos a esa sociedad; (b) debían incorporar imágenes y símbolos prototípicos que identifiquen ese país y su cultura; y (c) debían ser producidos en los últimos 10 ańos al momento de la evaluación. Se seleccionaron aquellas producciones que obtuvieron mayor porcentaje de acuerdo, las cuales fueron las películas Gran Torino (2008, dirigida por Clint Eastwood) y American Beauty (1999, dirigida por Sam Mendes).

En Gran Torino (GT) se escenifican relaciones interculturales diversas, marcadas a su vez por las relaciones intergeneracionales, en un sector de los Estados Unidos propio de los barrios populares con mayoría poblacional inmigrante. Ambos tipos de relación están marcados por el prejuicio, el conflicto intergrupal y la violencia, pero también por la receptividad y la disposición al diálogo y a establecer relaciones simétricas. La escenificación de la situación conflictiva que aparece inherente a estas relaciones, se acompaña de cambios que abren la posibilidad a formas alternativas de vinculación, enmarcadas, sin embargo, en un contexto violento.

En American Beauty (AB) las identidades sociales se presentan en medio de un debate en el plano de los valores, las ideologías y las relaciones intergeneracionales, desde una perspectiva interpersonal, 
intrafamiliar y etnoculturalmente homogénea. La escenificación identitaria acontece en un suburbio de clase media europeo-estadounidense, espacio donde se presenta la vida de varias familias como metáfora moral de la sociedad estadounidense.

Grupos de discusión. Esta técnica tiene como objetivo el estudio de la producción discursiva de un grupo de personas: permite indagar acerca del contenido producido, de las interacciones que llevaron a esta producción discursiva, del estudio de las secuencias de acción que posibilitaron el tipo de interacciones y de los discursos producidos (Lanmek, 1998; Valles, 1997; Gaskell \& Bauer, 2000; Pérez \& Víquez, 2009-2010). Para efectos del presente estudio esta técnica nos permitirió acceder al procesamiento sociocognitivo grupal de la propuesta fílmica, que permitió a su vez la generación compartida de procesos de categorización social y su resultante, identidades sociales asociadas a la recepción del material fílmico. Con ello fue posible identificar las particularidades de la categorización, la accesibilidad y la prominencia de categorías relevantes para la definición de la identidad.

Los grupos de discusión se iniciaron con la exposición visual a la película, seguido por el desarrollo de la discusión a partir de una guía compuesta de preguntas abiertas (por ejemplo, se solicitó una narración espontanea de la película, luego se hicieron preguntas como ¿cómo es la sociedad de la película?, ¿a qué país corresponde? ¿Con cuál de las dos sociedades se identifican más?). La guía se evaluó siguiendo la técnica de la entrevista cognitiva para la evaluación de instrumentos (Willis, 2005).

Cada grupo de discusión tuvo una duración promedio de 45 minutos. La moderación del grupo estuvo a cargo de una coordinadora y una asistente. La coordinadora dirigió la conversación, mientras que el/la asistente tomó notas, se ocupó del registro de la información y de los aspectos organizativos. Se promovió la producción argumentativa sobre los temas de discusión, fomentando la participación de todos los miembros. La discusión se registró tanto en audio como en video, esto con el fin de facilitar la transcripción. 
Se llevaron a cabo 5 grupos de discusión. Cada grupo estuvo compuesto por hombres y mujeres estudiantes de ciencias sociales y de ciencias naturales. Los tamaños de los grupos oscilaron entre 4 y 6 participantes. Para controlar el efecto del framing, se varió el orden de presentación de los filmes. Tres grupos vieron primero la película $\mathrm{A}$ y luego la película $\mathrm{B}$, mientras que los otros dos grupos vieron primero la película $\mathrm{B}$ y posteriormente la película $\mathrm{A}$.

\section{Análisis de datos}

Se recurrió al modelo propuesto por la Grounded Theory o Teoría Fundamentada (Strauss \& Corbin, 1998). Se trata de una estrategia abductiva de análisis, donde las categorías de análisis, hipótesis de investigación e interpretaciones están supeditadas a los datos, lo cual lo diferencia de los análisis de contenido clásico (Bauer \& Gaskell, 2000), en donde las categorías son definidas a priori, es decir, a partir de un marco teórico-hipotético predeterminado, que por lo demás impiden la emergencia de lo nuevo, a partir de una lógica de subsunción de los datos a teorías preestablecidas (Oevermann, 1991). A este procedimiento se le llama también método de comparación constante (Valles, 1997), cuyo objetivo original es la generación de teorías, recurriendo a la saturación de información como herramienta básica para su fundamentación.

Strauss y Corbin (1998) han sistematizado un procedimiento para la realización de esta propuesta de análisis de contenido, el cual sirvió de base para la realización de la presente investigación. Se pueden distinguir las siguientes fases: (a) codificación abierta, (b) codificación axial y (c) codificación selectiva. En la primera fase de codificación abierta, se hace una identificación de las categorías básicas, sus propiedades y dimensiones, para lo cual se seleccionan pasajes. Esta fase de codificación se realiza línea por línea. A la par de la definición de las categorías, se van sistematizando hipótesis, interpretaciones o problemas, para el posterior análisis. En la segunda fase de codificación axial, se procede a una especificación del sistema de categorías y subcategorías, sus dimensiones y propiedades. En la tercera fase de codificación 
selectiva, se procede a la presentación del modelo comprensivo que está a la base de las estructuras o procesos identificados en la fase anterior. Se trata propiamente de la sistematización teórica de las relaciones entre categorías y subcategorías anteriormente encontrados.

La codificación en la primera y segunda fase estuvo a cargo de dos codificadoras que analizaron de forma independiente el material de los grupos de estudio. Se realizó mediante el siguiente procedimiento de codificación: (a) entrenamiento de las codificadoras en el sistema de codificación inicial, previamente definido por el investigador principal; (b) las codificadoras procedieron a codificar de forma conjunta un protocolo, identificando dudas, sugiriendo correcciones en la codificación inicial, para finalmente definir de forma conjunta el sistema de codificación; (c) las codificadoras procedieron a analizar el material de forma independiente, realizándose reuniones periódicas o supervisiones para resolver dudas de interpretación de los códigos o crear nuevos; (d) finalizada la fase anterior, el investigador principal procede a revisar ambas codificaciones y revisar inconsistencias, las inconsistencias fueron nuevamente revisadas, esta vez de forma conjunta por ambas codificadoras.

En este estudio se presentan los resultados asociados a la representación del exogrupo y del endogrupo. Se trabajaron con subcategorías comunes a ambos films, con el fin de posibilitar la comparación de resultados. Estas subcategorías fueron: (a) Relaciones intergrupales, vinculadas con la percepción de las relaciones entre los grupos considerados por los participantes como constitutivos de las sociedades escenificadas; (b) Relaciones intragrupales, vinculadas con la percepción de las relaciones al interior del grupo; (c) Rasgos psicológicos, referidos a comportamientos o rasgos de personalidad considerados comunes a los integrantes de cada grupo; (d) Valores, relacionados con las orientaciones normativas la acción o pautas de comportamiento que distinguen a cada grupo; y (e) Valencia de las categorías anteriores, asociadas a la evaluación positiva o negativa atribuida a cada categoría. Se recurrió al software de análisis cualitativo Atlas.ti, versión 6, como herramienta informática para la codificación del material. 


\section{Resultados}

Los resultados que se presentan a continuación se concentran en la descripción de los contenidos que conforman la identidad social asociada a la categoría nación producto de la exposición a las películas. Para esto se describe el orden de prominencia de las diferentes categorías constituyentes de esta identidad social, así como la valencia o evaluación positiva o negativa de dichas categorías, haciendo referencia al contenido de la identidad atribuida tanto al endogrupo (Costa Rica) como al exogrupo (Estados Unidos).

Después de ver las películas Gran Torino (GT) y American Beauty $(\mathrm{AB})$, las personas hicieron referencia fundamentalmente al plano valorativo y a los rasgos psicológicos de los miembros del endogrupo (Costa Rica), en ese orden. Sin embargo, en comparación con GT, AB presentó un predominio de los rasgos psicológicos, mientras que en GT junto con estos rasgos, se presenta relevante el plano valorativo, seguido por las relaciones intragrupales, que tuvo una posición marginal en $A B$. De igual manera, solo en GT se hizo referencia a características asociadas a las relaciones integrupales. Las evaluaciones del endogrupo son fundamentalmente negativas en $\mathrm{AB}$, mientras que en GT son similarmente positivas y negativas. Específicamente, es en el plano valorativo donde predominan las evaluaciones negativas en $\mathrm{AB}$, mientras que en GT es en el plano de los rasgos psicológicos donde predominan las evaluaciones positivas.

Al comparar las categorizaciones del endogrupo y el exogrupo en ambas películas, se puede notar que en $A B$ hay predominio de enunciados referidos al endogrupo respecto al exogrupo. En el caso de GT se encontró un monto de categorización similar al referirse al exogrupo $\mathrm{y}$ al endogrupo.

Comparando la valencia de las evaluaciones realizadas entre el endogrupo y el exogrupo, se encontró que las evaluaciones más positivas se presentan al describir el endogrupo, independientemente del filme. No obstante, para el caso del exogrupo las evaluaciones son igualmente negativas tanto para GT como para AB. 


\section{Categorización endogrupal}

Considérese ahora el contenido de los atributos más relevantes de categorización endogrupal, es decir, los rasgos psicológicos comunes, el plano valorativo y las relaciones intragrupales.

La descripción de los rasgos psicológicos de valencia positiva atribuidos al endogrupo producto de la exposición de GT centra la categorización en el carácter anti-bélico atribuido a los costarricenses, expresado en rasgos como tranquilidad, actitud relajada o disposición comunicativa, que va acompañado de un carácter sociable y cálido. Por otro lado, se señalan otros rasgos como la felicidad, el tener un sentido de vida o la identificación positiva de sus pobladores con el país. Por el contrario, la descripción de valencia negativa hace referencia al carácter agresivo y prejuicioso respecto a los grupos étnicos e inmigrantes, así como a la pasividad y la adopción de estilos de vida estadounidenses. Producto de la exposición de $\mathrm{AB}$ no se presentan rasgos de valencia positiva. La descripción negativa, atribuye al endogrupo falsedad, la tendencia a orientarse por las apariencias y el dinero. Además se presenta un sector de la juventud como inadaptado y antisocial.

En el plano valorativo, luego de la exposición de GT, la descripción del exogrupo con valencia positiva se refiere a una sociedad orientada a la familia, que busca vivir en paz, de manera sencilla y segura. La búsqueda de la solidaridad y el desarrollo de las personas son un valor social e institucional importante. Se supone también una sociedad que busca la igualdad de sus integrantes. En cuanto a la caracterización con valencia negativa, la sociedad es más bien caracterizada como machista, prejuiciada, xenofóbica y con pérdida del sentido de seguridad. El cuido y respeto a las personas adultas mayores deja de ser un valor (ver Figura 1). 


\section{M1: Cuál de los dos países creen ustedes que se acerca más a un país ideal (,) digamos a lo que ustedes consideran un país ideal (?)}

O1GT: Ehhh (..) por lo que hablaba yo ahora digamos al menos para mí la mentalidad de América Central yo lo hago pensando en que todavía quedan (,) porque el costarricense es fundamentalmente (,) y no es por cuestiones políticas pero es fundamentalmente socialista (,) aunque no se dé cuenta (,) o sea la idiosincrasia es como a quién se le ocurre pedir por ejemplo no regalar algo que ocupa el vecino (,) el costarricense es de ayudar en parte (,) y se reconoce a nivel internacional verdad (!) que aquí somos (,) aunque es un slogan también (,) que aquí la gente es más ayudadora (,) como más amigable (,) entonces en ese sentido me parece que se puede volver a la iniciativa como para mejorar mientras que al menos lo que uno ve o escucha es que al menos en el EEUU de esa película que es como más estereotipada (,) cada uno agarra para su lado y la mentalidad es que se hace individualmente

\section{M1: O1GT (?)}

O1GT: yo siento que por ejemplo en cosas como el seguro o cosas así como la seguridad social (,) yo siento que tenemos muchas cosas así (,) o sea niveles de oportunidad para desarrollo individual somos el que mejor está y que (,) desarrollo individual es el que potencia el individuo y el desarrollo del país (,) por tanto

Figura 1. Ejemplo de categorización del endogrupo luego de la exposición de GT

En el contexto de la recepción de $\mathrm{AB}$, la valencia positiva en el plano valorativo supone un endogrupo orientado al bien común tanto en el plano de las relaciones sociales como de la relación con la naturaleza. Comparado con el exogrupo se le considera menos materialista, menos alienado y narcisista. La búsqueda del bienestar social, la felicidad en la familia, vivir la vida de forma tranquila, son horizontes de vida que organizan la actividad de las personas. En cuanto a la evaluación negativa se indican como características el machismo, la estandarización de los estilos de vida y la importación de modelos de Estados Unidos, aparentar lo que no se es, el consumismo, la superficialidad, la sobrevaloración de lo material como sustituto de la comunicación en la crianza de los hijos y las hijas, así como el autoritarismo paterno, la falta de honestidad, infidelidad, represión sexual, la resignación. 
En cuanto al plano de las relaciones intragrupales en la caracterización del endogrupo para el caso de GT, las descripciones con valencia positiva hacen énfasis en la orientación a la familia, como pauta cultural básica. El hecho de que todos se conozcan entre sí y que se viva en un ambiente de seguridad. Las descripciones con valencia negativa hacen referencia a falta de solidaridad, egoísmo y cambios culturales negativos asociados a una mayor inseguridad, irrespeto hacia las personas adultas mayores y una percepción de la realidad como más problemática. Además, se indica que las parejas homosexuales no tienen la posibilidad de presentarse abiertamente como tales.

En $\mathrm{AB}$ el plano de las relaciones intragrupales no presenta valencia positiva. Las evaluaciones de valencia negativa, indican la falta de comunicación con los vecinos o el distanciamiento comunicativo respecto a la familia, la superficialidad en las relaciones con extraños y las limitaciones para que las parejas homosexuales se presenten públicamente como tales.

\section{Categorización exogrupal}

En la categorización producto de la exposición de GT, predominaba el plano valorativo, seguido por los rasgos psicológicos, las relaciones intragrupales y las relaciones intergrupales. En el caso de $A B$, predomina igualmente la descripción valorativa, seguida, no obstante, por las relaciones intragrupales y los rasgos psicológicos. El plano de las relaciones intergrupales ocupa aquí una posición marginal. Es importante señalar que, en el caso de GT, los participantes tematizaron la tensión entre el grupo social mayoritario, representado por el personaje principal de la película y un grupo inmigrante de origen asiático, con el que se desarrollan buena parte de las interacciones en la película. Las evaluaciones del exogrupo en ambas películas son fundamentalmente negativas. En el caso de $\mathrm{AB}$ el plano valorativo es claramente el más negativo de todos. En la recepción de GT todos los componentes de la calificación son predominantemente negativos. No obstante, en el ámbito valorativo es donde se pueden apreciar más 
evaluaciones positivas, al comparar los componentes con las evaluaciones positivas de $\mathrm{AB}$.

Para el caso de GT, de los rasgos psicológicos de valencia negativa atribuidos al exogrupo, se le señala como individualista, materialista y agresivo, con un estilo de vida rutinario, orientado al trabajo. Se indican que se pueden identificar dos grupos generacionales: la generación mayor es conservadora y fría, la más joven es consumista y sin valores. Paralelamente está la cultura Hmong inmigrante (grupo étnico asiático presente en la película) que se le caracteriza como conservadora. Los rasgos con valencia positiva están asociados a la tolerancia, cosmopolitismo y en el caso del grupo inmigrante, a la responsabilidad.

En el caso de $\mathrm{AB}$, los rasgos psicológicos de valencia negativa son los predominantes. Estos se asocian con el énfasis exacerbado por el éxito individual, la falta de comunicación, el ser fríos en el plano interpersonal, infelices y con una vida rutinaria y estresada.

En el contexto de la recepción de GT los valores de valencia negativa del exogrupo se refieren al militarismo, consumismo, menosprecio a la persona adulta mayor, se trata de una cultura de lo fugaz, donde las pandillas son una forma de vida. En cuanto a los valores de valencia positiva, se señala el reconocimiento de la inmigración y los inmigrantes. En el caso del grupo inmigrante escenificado, se refieren al respeto por las personas adultas mayores, al considerarlos portadores de la tradición.

Para el caso de la exposición de $\mathrm{AB}$, los valores de valencia negativa se refieren a la tendencia a guiarse por las apariencias, estereotipos, el éxito económico asociado a una carencia de sentido de la vida y de descuido de lo esencial. Se caracterizan también por el consumismo, materialismo, individualismo y la falta de solidaridad, la hipocresía, la infelicidad, el vivir una vida pre-programada y la homofobia. Como valores de valencia positiva se señalan la tolerancia a la homosexualidad, el militarismo como expresión de nacionalismo, la cortesía y el hecho de ser una potencia desarrollada (ver Figura 2). 
M1: cómo describirían el país que se ve en la película American Beauty (?) 0203AB: en Estados Unidos aunque la gente sea pobre (,) tiene ese modelo de vida digamos (,) quiere parecerse a tal o quiere tener tal carro y todo entonces (,) en cuanto a cómo es el país (,) yo me imagino que es un país (,) lleno de estereotipos (,) consumista (,) aunque usted sea pobre o no (,) hay estereotipos (,) aunque usted sea pobre o no (,) es consumista (,) y está lleno de un montón de ideas falsas como cómo tiene que ser el hombre (,) cómo tiene que ser la mujer (,) cómo tiene que comportarse la hija (,) qué tiene que hacer uno (,) que no tiene que hacer (..) tal vez lleno de estereotipos (,) de ideas falsas.

Figura 2. Ejemplo de categorización del exogrupo luego de la exposición de $\mathrm{AB}$.

Las relaciones intragrupales de valencia negativa del exogrupo de GT son descritas como superficiales, por las diferencias conflictivas entre los grupos que componen el país, la discriminación de minorías y extranjeros y los problemas de integración de estos últimos. Las relaciones intragrupales de valencia positiva se refieren a la similitud entre el exogrupo y el endogrupo al representar la dinámica de las relaciones entre hermanos. En cuanto al grupo inmigrante se señala que cada integrante del grupo se considera a sí-mismo representante del mismo. Igualmente se plantea que el cortejo en este grupo es más respetuoso. En cuanto a la recepción de $\mathrm{AB}$, se indica que las relaciones intragrupales de valencia negativa se caracterizan por el odio, la violencia, las relaciones dañinas, utilitarias y faltas de comunicación. Al interior de la familia estas relaciones se plantean como disfuncionales y poco saludables, individualistas, donde sus miembros son distantes. A nivel de las evaluaciones de valencia positiva, se indica la cortesía como un recurso empleado por deseabilidad social.

\section{Discusión}

Luego de la exposición de ambos filmes, se presenta un claro favoritismo endogrupal, por cuanto las evaluaciones más positivas se asocian al endogrupo y las negativas al exogrupo. En la recepción mediática 
acontecen mecanismos básicos propios de la identidad social, resultando posible distinguir no solo un endogrupo y un exogrupo, sino también activándose un favoritismo endogrupal, en este caso asociado a la categoría de nación, que en lo referente a los participantes consultados se caracteriza por ser un favoritismo crítico. Así la recepción de filmes se puede ver como un espacio para la consolidación, pero también para el cuestionamiento de las identidades sociales, reproduciendo o relativizando estereotipos y prejuicios existentes. Ahora bien, los encuadres ofrecidos por las películas definen la forma cómo se organizan las identidades sociales. Esto supone la construcción comunicativa de diferentes identidades que ponen de manifiesto particularidades que son evocadas por los encuadres propios del filme, pero también aspectos comunes que dan cuenta de contenidos estables de las identidades colectivas compartidas, que se mantienen independientemente del ofrecimiento fílmico. Como indica Harwood y Roy (2005), el mensaje mediático va a aportar al contenido y organización categorial de la identidad, las actitudes asociadas a la evaluación de los grupos de referencia y de contraste y a la percepción de la vitalidad grupal en la relación intergrupal.

En comparación con la película de GT, en $\mathrm{AB}$ se presentó un predominio de los rasgos psicológicos al describir al endogrupo, mientras que en GT junto con estos rasgos, se presenta relevante el plano valorativo, seguido por las relaciones intragrupales, que tuvo una posición marginal en AB. De igual manera, solo en GT se hizo referencia a características asociadas a las relaciones intergrupales. Las evaluaciones del endogrupo son fundamentalmente negativas en $A B$, en GT son similarmente positivas y negativas. Esta forma de organización de la representación corresponde con el contenido de los filmes, debido a que en $\mathrm{AB}$ se presenta una visión más estereotipada de los personajes. Por un lado, en $A B$ la narración se centra en la psicología de los personajes, mientras que en GT la atención está puesta en las relaciones entre los diferentes grupos en interacción y conflicto, y los valores que se ponen en juego.

Al comparar con la categorización del exogrupo, se puede notar que en $A B$ hay mayor presencia de enunciados referidos al endogrupo 
en contraposición al exogrupo. En el caso de GT se encontró una dirección de categorización inversa, es decir, la categorización exogrupal fue mayor que la endogrupal. Con ello se puede apreciar cómo los filmes generaron focos de evaluación diferentes, después la exposición de $\mathrm{AB}$ los grupos orientaron sus evaluaciones, predominantemente negativas, hacia el endogrupo, mientras que en GT las evaluaciones, también negativas, se orientaron hacia el exogrupo. Después de la exposición de GT, se construye en el contexto de la discusión grupal un endogrupo, es decir, una representación de Costa Rica, que es caracterizado por estarse alejando de su pasado tradicional, colectivista y orientado a la familia, para acercarse a las características propias de una sociedad capitalista, cuyo referente son los Estados Unidos, centrada en el consumo como criterio de distinción identitaria que se aleja de la autenticidad, rasgo intrínseco de una identidad ideal. $\mathrm{Al}$ referirse al exogrupo, se hace mención a un contexto sociocultural propio de las sociedades modernas desarrolladas, poniendo como referente no solo el consumismo y las tensiones entre autenticidad versus falsedad o apariencia, sino también a la conflictividad intragrupal, la discriminación y la violencia.

Por su parte, luego de la exposición de $A B$ la representación del endogrupo presenta semejanzas y diferencias respecto a lo sucedido con GT. La asociación entre consumismo y falsedad se mantienen como características del endogrupo, alejándose igualmente del ideal de autenticidad. No obstante, se hace énfasis en los problemas comunicativos, la estandarización de los estilos de vida y la moral conservadora. En tensión con la descripción actual, se afirma la vigencia de una sociedad organizada alrededor de la solidaridad, la igualdad y la familia, como aspectos característicos del endogrupo. En $\mathrm{AB}$ se presenta una descripción más exacerbada del exogrupo, haciendo mayor énfasis en el plano valorativo y la criticidad hacia el modelo de sociedad propia de los países desarrollados occidentales, señalando la orientación hacia el individualismo, el consumismo, el trabajo y el éxito como únicos criterios organizadores del ciclo vital. De manera semejante al endogrupo, pero igualmente de forma más negativa y dramática, se considera una sociedad con problemas comunicativos, conflictividad intrafamiliar, 
poco solidaria, violenta, conservadora y alejada del modelo ideológico de familia nuclear. A diferencia la exposición de GT no están presentes los problemas de discriminación, xenofobia y la conflictividad al interior de los grupos que conforman esa sociedad.

Después de la exposición de ambas películas se puede distinguir un núcleo común en torno a la descripción del endogrupo, en este caso Costa Rica, como categoría nacional organizadora de la identidad social. Común es en ambos la percepción de una sociedad tradicional en extinción, centrado en la familia, pero también en un modelo solidario de convivencia, para abrirse paso a una sociedad individualista, o como diría Honneth (1995), un modelo de sociedad donde la privatización del mundo social es lo que impera y que se acerca precisamente a la representación del exogrupo (es decir, Estados Unidos, en este caso). Precisamente esta sociedad fue caracterizada por el consumismo, la estandarización del estilo de vida y la maleabilidad identitaria de acuerdo a las demandas del mercado. Las diferencias entre las representaciones de la identidad social son aportadas por las particularidades de ambos filmes: por un lado, atendiendo a los problemas de discriminación y conflictividad social, aspectos evocados por GT, y por otro lado, dirigiéndose a problemas asociados a las relaciones familiares, pautas comunicativas y el conservadurismo, presentes en $\mathrm{AB}$.

Resulta interesante el carácter negativo de las evaluaciones, que aunque menor en comparación con el exogrupo, es el predominante en las evaluaciones del endogrupo. Al respecto no se encontraron tendencias nacionalistas, que exaltaran al endogrupo y su supremacía, aunque sí se aprecian algunos contenidos asociados a patriotismo, sobre todo los referidos a la ya citada percepción de la pérdida del modelo de sociedad tradicional o la afirmación de ciertas particularidades institucionales y de las relaciones interpersonales atribuidas al país. De hecho, las descripciones exogrupales, evaluadas de forma más negativa, hacen referencia a los aspectos valorativos, de rasgos o de interacción, precisamente rechazados en el endogrupo. Todo ello explica que tampoco se aprecie una tendencia a la sumisión exogrupal, en donde tanto la identificación endogrupal como la despersonalización exogrupal son 
mecanismos que se presentan de forma marginal entre las personas participantes. De forma hipotética se podría plantear que es posible que si el grupo, en este caso el país de comparación, fuera otro, las percepciones tanto del endogrupo como del exogrupo podrían modificarse, manteniendo, sin embargo puntos de categorización estable, como es el referido al plano valorativo o los rasgos psicológicos. Este es un aspecto muy relevante que es necesario investigar a futuro.

El estudio realizado resulta relevante pues ofrece indicios sobre el carácter contextual y comunicativo de la formación de las identidades sociales, particularmente de las asociadas a la categoría nación, poniendo en cuestión la rigidez con la que muchas veces se tratan este tipo de identidades. Los resultados aportados ofrecen material relevante para el desarrollo de instrumentos y para el diseño de estudios experimentales que permitan analizar este fenómeno de manera más precisa, que posibiliten identificar las asociaciones entre las variables, así como las relaciones de causalidad dentro de modelos multivariados. A su vez, el estudio del tipo de estatus del país, podría dar información al respecto. De igual manera, la variación del tipo o género del filme es un factor que debe evaluarse. Finalmente, es necesario igualmente identificar cuáles otras variables de tipo sociocontextuales, de personalidad o de procesamiento cognitivo y emocional pueden intervenir en la asociación entre estos aspectos.

\section{Referencias}

Abrams, J. Giles, H. \& Reid, S. (2004). A social identity model of media usage and effects. Zeitschrift für Medienpsychologie, 16, 17-25.

Abrams, J. \& Giles, H. (2007). Ethnic Identity Gratifications Selection and Avoidance by African Americans: A Group Vitality and Social Identity Gratifications Perspective. Lawrence Erlbaum Associates, Inc. Media psychology, 9(1), 115-134.

Bauer, M. \& Gaskell, G. (2000). Qualitative researching with text, image and sound. London: Sage. 
Eastwood, C. (Productor y Director) (2008). Gran Torino [Película]. Burbank: Warner Brothers Pictures.

García Canclini, N. (1989). Culturas hibridas: Estrategias para entrar y salir de la modernidad. México: Grijalbo.

Harwood, J (1999). Age identifications, social identity gratifications, and television viewing. Journal of broadcasting and electronic media, 43, 123-146.

Harwood, J. \& Roy, A. (2005). Social Identity Theory and Mass Communication Research. En J. Harwood \& Howard Giles (Eds.), Intergroup Communication. Multiple Perspectives (pp. 189212). New York: Peter Lang.

Honneth, A. (1995). Desintegration. Bruchstücke einer soziologischen Zeitdiagnose. Frankfurt: Fischer.

Livingstone, S. (1998). Making Sense of Television: The Psychology of Audience Interpretation (2da Edición). London: Routledge

Martín Barbero, J. (2002). La globalización en clave cultural: una mirada latinoamericana. En Efectos Globalismo y pluralismo. Montreal: Coloquio Internacional. Recuperado de http://www. er.uqam.ca/nobel/gricis/actes/bogues/Barbero.pdf

McGarty, C. (1999). Categorization in social psychology. London: Sage Publications.

Mendes, S. (Director), Cohen, B. \& Jinks, D. (Productores) (1999). American Beauty [Película]. Dremworks Pictures.

Oervermann, U. (1991). Genetischer Strukturalismus und das sozialwissentschaftliche Problem der Erklärung der Entstehung des Neues. En S. Müller-Doohm (Ed.), Jenseits der Utopie (pp. 267-336). Frankfurt: Suhrkamp

Pérez, R. (2002). Televisión, juventud y cambio cultural: recepción de series de televisión y la construcción de representaciones acerca del futuro en jóvenes costarricenses y alemanes. Actualidades en Psicología, 18, 17-48.

Pérez, R. (2003a). Globalización intercultural e investigación intercultural en psicología social: apuntes para la problematización de un vínculo ignorado. Revista Ciencias Sociales, 100, 165-178. 
Pérez, R. (2003b). Psicología social de la comunicación de masas: introducción a las teorias psicosociales de la comunicación de masas. San José: IIP-UCR, SIEDIN.

Pérez, R. \& Víquez, D. (2009-2010). Grupos de discusión y cogniciones sociales. En busca de una metodología adecuada para el estudio de las cogniciones sociales. Revista Actualidades en Psicologia, 23-24, 87-101.

Scheufele, D. (1999). Framing as a theory of media effects. Journal of communication, 49, 103-122.

Scheufele, D. (2004). Framing-effects approach: A theoretical and methodological critique. Comunications, 29, 401-428.

Strauss, A. \& Corbin, J. (1998). Basics of Qualitative Research. Techniques and procedures for Developing Grounded Theory. California, EUA: SAGE Publications.

Tajfel, H. (1984). Grupos Humanos y Categorias Sociales. Estudios de Psicología Social. Barcelona: Herder.

Trepte, S. (2006). Social Identity Theory. En J. Bryant \& P. Vorderer (Eds.), Psicology of Entertainment (pp. 255-272). New Jersey: Lawrence Erlbaum Associates.

Turner, J. \& Reynolds, K. (2003). The Social Identity Perspective in Intergroup Relations: Theories, Themes, and Controversies. En R. Brown y S. Guertner (Eds.), Blackwell Handbook of Social Psychology. Intergroup Processes (pp. 133-152). UK: Blackwell.

Valles, M. (1997). Técnicas cualitativas de investigación social. Reflexión metodológica y práctica profesional. Madrid: Editorial Síntesis.

Willis, G. (2005). Cognitive Interviewing. A tool for improving Questionnaire Design. UK: Sage.

Recibido: 07 de enero, 2014 Aceptado: 14 de noviembre, 2014 